\title{
PENGARUH TOTAL QUALITY MANAGEMENT (TQM) DAN KEDISIPLINAN GURU TERHADAP KINERJA GURU SMA/SMK DI KOTA MADIUN
}

\author{
Budi Sri Supeni \\ Magister Akuntansi Universitas Sebelas Maret
}

\begin{abstract}
ABSTRAK
Untuk meningkatkan kinerja guru dalam suatu sekolah dibutuhkan beberapa faktor, diantaranya total quality management dan kedisiplinan. Penelitian ini bertujuan untuk mengetahui total quality management dan kedisiplinan berpengaruh secara bersama-sama, secara parsial terhadap kinerja guru. Pengukuran terhadap TQM, kedisiplinan dan kinerja guru diperoleh dari penyebaran instrumen angket. Penelitian ini menggunakan data primer dan kwantitatif dari 720 guru SMA/SMK di kota Madiun diambil 80 guru dengan pengolahan data regresi beganda.Berdasarkan penelitian yang telah dilakukan sebelum maupun sesudah memasukan variabel kontrol, ditemukan bahwa variabel indipenden, total quality management (TQM), dan kedisiplinan guru berpengaruh signifikan terhadap kinerja guru. Total quality management yang merupakan variabel kontrol juga mempengaruhi kinerja guru sebesar 21,6\%, dan kedisiplinan guru juga berpengaruh signifikan terhadap kinerja guru sebesar $56,9 \%$. Sehingga dapat disimpulkan jika total quality management dan kedisiplinan guru yang baik maka semakin baik pula kinerja guru SMA/SMK di kota Madiun.Dari hasil penelitian ini diharapkan dapat digunakan sebagai masukan bagi guru, sekola, dinas pendidikan dan instansi terkait untuk meningkatkan mutu layanan kepada pelanggan/siswa dan peningkatan kinerja guru.
\end{abstract}

Kata kunci : total quality management, kedisiplinan guru, kinerja guru

\section{PENDAHULUAN}

Pendidikan nasional bertugas dan bertanggung jawab untuk menghantar bangsa ini agar siap menyongsong dan mampu bersaing dalam era globalisasi serta meningkatkan kualitas hidup, kehidupan bangsa dan negara di masa depan. Pendidikan perlu mengambil alih posisi dan peran nyata yang dinamis, proaktif, interaktif dan berorientasi ke masa depan. Sekolah sebagai sebuah lembaga pendidikan dalam rangka mencapai tujuan, yaitu menciptakan sumber daya manusia yang berprestasi, handal dan mampu bersaing dalam dunia nyata, maka sekolah dituntut untuk mampu melaksanakan proses kegiatan belajar mengajar dengan tertib, terarah dan berkesinambungan.

Ngalim Purwanto (2006) menegaskan bahwa tujuan pendidikan, selain membentuk manusia susila yang cakap, juga manusia yang bertanggung jawab atas kesejahteraan masyarakat dan tanah air. Jelaslah bahwa seorang guru harus seorang yang bertanggung jawab dan berdisiplin diri. Sebagai seorang guru, tentu saja pertama-tama harus bertanggung jawab kepada tugasnya sebagai guru, yaitu mengajar dan mendidik anak-anak yang telah dipercayakan kepadanya. Di samping itu, tidak boleh pula dilupakan tugas-tugas dan pekerjaannya menjadi memerlukan tanggung jawabnya, antara lain: (1) penguasaan kurikulum, (2) 
penguasaan setiap materi pelajaran; (3) penguasaan metode dan teknik evaluasi; (4) komitmen terhadap tugas; (5) disiplin dalam arti luas.

Kualitas tenaga pengajar (dalam hal ini guru) merupakan salah satu faktor penentu tinggi rendahnya kualitas hasil pendidikan. Posisi strategi guru untuk meningkatkan mutu hasil pendidikan sangat dipengaruhi oleh kemampuan profesional, faktor kesejahteraan, disiplin kerja, motivasi kerja serta sarana prasarana dari sekolah itu sendiri. Lingkungan persaingan yang tajam dan bersifat global menuntut sekolah meningkatkan mutu dan keunggulan daya saing yang dipengaruhi 4 faktor yaitu mutu, fleksibilitas, kecepatan dan biaya yang rendah. Sejak tahun 1980-an Total quality management (TQM) dikembangkan sebagai salah satu alat untuk memperbaiki kinerja melalui perbaikan kualitas pada seluruh aspek organisasi. Program TQM menitik beratkan pada kualitas secara total dalam organisasi. Beberapa sekolah ada yang telah menerapkan TQM dan berhasil meningkatkan kinerjanya, namun ada juga yang belum mampu meningkatkan kinerjanya. Total quality management (TQM) juga merupakan suatu pendekatan yang mencoba untuk memaksimumkan daya saing organisasi melalui continuous improvement (perbaikan terus menerus) atas produk, jasa, manusia, proses dan lingkungannya.

Tidak kalah penting dalam mencapai tujuan sekolah adalah kedisiplinan kerja. Kedisiplinan karyawan adalah sifat seorang karyawan yang secara sadar mematuhi aturan dan peraturan organisasi tertentu. Kedisiplinan bisa dipandang sebagai bentuk kewajiaban bagi guru dalam melaksanakan aturan-aturan sekolah. Semakin tinggi kedisiplinan maka semakin tinggi produktifitas kerja guru dan kinerja sekolah; cateris paribus.

Masalah kinerja menjadi sorotan berbagai pihak, kinerja pemerintah akan dirasakan oleh masyarakat dan kinerja guru akan dirasakan dan disoroti siswa serta orang tua siswa. Kondisi kerja guru di SMA/SMK di kota Madiun dalam berbagai hal masih banyak yang belum menunjukkan kinerja yang baik. Pada umumnya kurang baiknya kinerja guru SMA/SMK di kota Madiun berhubungan dengan kedisiplinan : kurang siapnya guru menyusun perangkat kegiatan belajar mengajar (KBM), terlambatnya memberikan ulangan harian, tingkat kehadiran di kelas yang rendah.

Ketidakhadiran mengindikasikan tiga hal secara bersamaan : pertama adalah kinerja yang rendah dari para guru. Ketidakhadiran di tempat kerja akan berpengaruh pada hasil kerja guru, semakin sering tidak hadir maka semakin rendah hasil kerja yang didapatkan, kedua adalah ketidakhadiran yang tinggi juga mengindikasikan rendahnya disiplin dan motivasi kerja dari seorang guru, ketiga :seseorang yang merasa malas untuk bekerja akan enggan berangkat, terutama jika ketidakhadirannya tidak disertai dengan keterangan yang jelas.

Kinerja guru adalah kemampuan seorang guru untuk melakukan perbuatan sesuai dengan tujuan yang telah ditetapkan, yang mencakup aspek perencanaan program belajar mengajar, pelaksanaan proses belajar mengajar, penciptaan dan pemeliharaan kelas yang optimal, pengendalian kondisi belajar yang optimal, serta penilaian hasil belajar. Kinerja sangat penting dalam menentukan kualitas kerja seseorang, termasuk seorang guru.

Sebagai gambaran profil guru yang kinerjanya masih rendah antara lain: guru mengajar secara monoton dan tanpa persiapan yang matang. Guru masih menggunakan persiapan mengajar dengan sangat sederhana, belum sepenuhnya 
menggunakan acuan kurikulum yang dipersyaratkan, dan tidak konsisten dalam implementasi skenario rencana pelaksanaan pembelajaran (RPP) yang telah dipersiapkan dan pada proses pembelajaran guru masih dominan menggunakan metode ceramah. Penurunan kinerja guru SMA/SMK di kota Madiun langsung maupun tidak langsung mengakibatkan penurunan prestasi belajar siswa.

\section{METODOLOGI PENELITIAN}

Penelitian ini termasuk penelitian korelasional. Populasi penelitian ini adalah seluruh guru SMA/SMK di kota Madiun sebanyak 720 orang. Pengambilan sampel dalam penelitian ini dilakukan secara stratified Propotional Random Sampling. Besar sampel penelitian ini adalah 80 orang. Jenis data digunakan dalam penelitian ini adalah data kuantitatif yaitu data yang langsung diperoleh dari sumber (responden), data analisis dengan menggunakan teknik regresi. Analisis data dilakukan dengan menggunakan rumus Multiple Regression menggunakan aplikasi statistik SPSS dan Stepwise.

\section{HASIL PENELITIAN}

\section{Distribusi Data Total quality management Guru SMA/SMK di kota Madiun}

Skor maksimum total quality management dari jawaban responden diperoleh skor tertinggi 63 dan skor terendah 39. Untuk mencari kelas interval adalah

rentang kelas $=$ skor maksimal - skor minimal.

$$
\begin{aligned}
& =63-39 \\
& =24
\end{aligned}
$$

Banyak kelas interval $=1+(3,3) \log \mathrm{N}$

$$
\begin{aligned}
& =1+(3,3) \log 80 \\
& =1+(3,3) 1,903 \\
& =7,28=7
\end{aligned}
$$

\begin{tabular}{|c|c|c|c|c|}
\hline No & Nilai Interval & $\mathrm{Xi}$ & $\mathrm{F}$ & Prosentase \\
\hline 1 & $63-66$ & 65 & 1 & $1,25 \%$ \\
\hline 2 & $59-62$ & 61 & 1 & $1.25 \%$ \\
\hline 3 & $55-58$ & 57 & 3 & $3,75 \%$ \\
\hline 4 & $51-54$ & 53 & 19 & $23.75 \%$ \\
\hline 5 & $47-50$ & 49 & 32 & $40 \%$ \\
\hline 6 & $43-46$ & 45 & 17 & $21,25 \%$ \\
\hline 7 & $39-42$ & 41 & 7 & $8,75 \%$ \\
\hline \multicolumn{3}{|c|}{ Jumlah } & 80 & $100 \%$ \\
\hline
\end{tabular}

Panjang kelas $=$ rentang kelas $:$ banyak kelas

$$
\begin{aligned}
& =24: 7 \\
& =3,43=3
\end{aligned}
$$

Table 1 : Distribusi Frekuensi Skor Variabel TQM 
Berdasarkan tabel 1 di atas tergambar jelas tentang frekuensi tertinggi 47 50 dengan frekuensi relatif sebanyak 32, sedangkan frekuensi terendah sebanyak 1. Berdasarkan pengolahan data angket variabel total quality management $\left(\mathrm{X}_{1}\right)$ dengan cara membandingkan skor rata-rata (mean) 48,9125 dibagi dengan skor maksimal 63 dikali 100\%, maka 48,9125: 63 x 100\%, maka diperoleh angka 0,77 $\mathrm{x} 100 \%=77 \%$. Hal ini berarti variabel total quality management guru SMA/SMK di kota Madiun berada pada kategori "tinggi” yaitu sebesar 77\% dari skor ideal.

\section{Distribusi Data Kedisiplinan Guru SMA/SMK Di Kota Madiun}

Skor maksimum kedisiplinan guru dari jawaban responden diperoleh skor tertinggi 64 dan skor terendah 36. Untuk mencari kelas interval adalah

rentang kelas $=$ skor maksimal - skor minimal.

$$
\begin{aligned}
& =64-36 \\
& =28
\end{aligned}
$$

Banyak kelas interval $=1+(3,3) \log \mathrm{N}$

$$
\begin{aligned}
& =1+(3,3) \log 80 \\
& =1+(3,3) 1,903 \\
& =7,28=7
\end{aligned}
$$

\begin{tabular}{|c|c|c|c|c|}
\hline No & Nilai Interval & $\mathrm{Xi}$ & $\mathrm{F}$ & Prosentase \\
\hline 1 & $61-65$ & 63 & 5 & $6,25 \%$ \\
\hline 2 & $56-60$ & 58 & 5 & $6,25 \%$ \\
\hline 3 & $51-55$ & 53 & 13 & $16,25 \%$ \\
\hline 4 & $46-50$ & 48 & 36 & $45 \%$ \\
\hline 5 & $41-45$ & 43 & 16 & $20 \%$ \\
\hline 6 & $36-40$ & 38 & 5 & $6,25 \%$ \\
\hline \multicolumn{3}{|c|}{ Jumlah } & 80 & $100 \%$ \\
\hline
\end{tabular}

Panjang kelas $=$ rentang kelas $:$ banyak kelas

$$
\begin{aligned}
& =28: 7 \\
& =4
\end{aligned}
$$

Table 2 : Distribusi Frekuensi Skor Variabel Kedisiplinan Guru

Berdasarkan tabel 2 di atas tergambar jelas tentang frekuensi tertinggi 46 50 dengan frekuensi relatif sebanyak 36, sedangkan frekuensi terendah sebanyak 5. Berdasarkan pengolahan data angket variabel kedisiplinan guru $\left(\mathrm{X}_{2}\right)$ dengan cara membandingkan skor rata-rata (mean) 49,0250 dibagi dengan skor maksimal 64 dikali 100\%, maka 49,0250: 64 x 100\%, maka diperoleh angka 0,76 x 100\%= $76 \%$. Hal ini berarti variabel kedisiplinan guru SMA/SMK di kota Madiun berada pada kategori "tinggi" yaitu sebesar 76\% dari skor ideal.

\section{Distribusi Data Kinerja Guru SMA/SMK Di Kota Madiun}

Skor maksimum kinerja guru dari jawaban responden diperoleh skor tertinggi 66 dan skor terendah 36. Untuk mencari kelas interval adalah 
rentang kelas $=$ skor maksimal - skor minimal.

$$
\begin{aligned}
& =66-36 \\
& =30
\end{aligned}
$$

Banyak kelas interval $=1+(3,3) \log \mathrm{N}$

$$
\begin{aligned}
& =1+(3,3) \log 80 \\
& =1+(3,3) 1,903=7,28=7
\end{aligned}
$$

\begin{tabular}{|c|c|c|c|c|}
\hline No & Nilai Interval & $\mathrm{Xi}$ & $\mathrm{F}$ & Prosentase \\
\hline 1 & $66-70$ & 68 & 1 & $1,25 \%$ \\
\hline 2 & $61-65$ & 63 & 7 & $8,75 \%$ \\
\hline 3 & $56-60$ & 58 & 19 & $23,75 \%$ \\
\hline 4 & $51-55$ & 53 & 13 & $16,25 \%$ \\
\hline 5 & $46-50$ & 48 & 26 & $32,5 \%$ \\
\hline 6 & $41-45$ & 43 & 10 & $12,5 \%$ \\
\hline 7 & $36-40$ & 38 & 4 & $5 \%$ \\
\hline \multicolumn{3}{|c|}{ Jumlah } & 80 & $100 \%$ \\
\hline
\end{tabular}

Panjang kelas $=$ rentang kelas $:$ banyak kelas

$$
\begin{aligned}
& =30: 7 \\
& =4,285=4
\end{aligned}
$$

Table 3 : Distribusi Frekuensi Skor Variabel Kinerja Guru

Berdasarkan tabel 3 di atas tergambar jelas tentang frekuensi tertinggi 46 50 dengan frekuensi relatif sebanyak 26, sedangkan frekuensi terendah sebanyak 1. Berdasarkan pengolahan data angket variabel kinerja guru (Y) 52,0125 dengan cara membandingkan skor rata-rata (mean) 49,0250 dibagi dengan skor maksimal 66 dikali 100\%, maka 52,0125: $66 \times 100 \%$, maka diperoleh angka 0,78 x 100\%= $78 \%$. Hal ini berarti variabel kinerja guru SMA/SMK di kota Madiun berada pada kategori "tinggi" yaitu sebesar $78 \%$ dari skor ideal.

\section{Pengaruh Total quality management Dan Kedisiplinan Guru Terhadap Kinerja Guru SMA/SMK Di Kota Madiun}

Berdasarkan analisis data antara variabel total quality management dan kedisiplinan guru terhadap kinerja guru SMA/SMK di Kota Madiun diperoleh $r_{\text {hitung }}=0,533>r_{\text {tabel }} 0,220$ pada taraf signifikan $95 \%$ dengan $\mathrm{N}=80$.

Tabel 4 : Pengujian Koefisien Korelasi Variabel $\mathrm{X}_{1}, \mathrm{X}_{2}$ dan $\mathrm{Y}$ dengan tabel uji $\mathrm{r}$ dan tebel uji $\mathrm{t}$

\begin{tabular}{|c|c|c|c|}
\hline $\mathrm{r}_{\text {hitung }}$ & $\begin{array}{c}\mathrm{r}_{\text {tabel }} \text { pada taraf } \\
\text { signifikan 95\% }\end{array}$ & $\mathrm{t}_{\text {hitung }}$ & $\begin{array}{c}\mathrm{t}_{\text {tabel }} \text { pada taraf } \\
\text { signifikan 95\% }\end{array}$ \\
\hline$-0,194$ & 0,220 & $-1,532$ & 1,664 \\
\hline 0,512 & 0,220 & 5,148 & 1,664 \\
\hline
\end{tabular}




\section{PEMBAHASAN}

Sebagaimana telah dijelaskan dalam kajian teori pada penelitian ini dinyatakan bahwa kinerja guru dipengaruhi oleh banyak faktor, diantaranya adalah total quality management dan kedisiplinan guru. Hasil pengolahan data pada penelitian ini menemukan bahwa total quality management dan kinerja guru SMA/SMK di Kota Madiun mempunyai pengaruh yang signifikan (nyata) terhadap kinerja guru pada taraf signifikan 95\% dengan koefisien korelasi TQM 0,194 dan kedisiplinan guru 0,512. Untuk lebih jelasnya berikut ini akan diuraikan pembahsan masing-masing variabel.

\section{Total quality management}

Berdasarkan data yang diperoleh dari responden dan dengan membandingkan skor rata-rata dengan skor maksimal dikali $100 \%$ dapat diketahui bahwa penilaian secara kuantitatif mengenai total quality management guru SMA/SMK di Kota Madiun berada pada kategori tinggi (77\% dari skor ideal). Hal ini berarti total quality management guru perlu untuk ditingkatkan agar menjadi lebih baik lagi. TQM berpengaruh 21,6\% terhadap kinerja guru.

Adapun usaha-usaha yang menimbulkan dan mendorong peningkatan total quality management agar dapat mencapai tujuan organisasi secara optimal yaitu, meningkatkan kepuasan pelanggan (siswa), meningkatkan mutu, meningkatkan kerjasama.

\section{Kedisiplinan Guru}

Berdasarkan data yang diperoleh dari responden dan dengan membandingkan skor rata-rata dengan skor maksimal dikali $100 \%$ dapat diketahui bahwa penilaian secara kuantitatif mengenai total quality management guru SMA/SMK di Kota Madiun berada pada kategori tinggi (76\% dari skor ideal). Hal ini berarti kedisiplinan guru perlu untuk ditingkatkan agar menjadi lebih baik lagi. Kedisiplinan berpengaruh 56,9\% terhadap kinerja guru.

Usaha agar kedisiplinan guru agar lebih meningkat lagi yaitu guru memperhatikan kesejahteraan guru, memberikan pelatihan kepada guru, memberikan banyak kesempatan kepada guru untuk menyampaikan aspirasi mereka melalui pendapat, kritik dan saran yang sifatnya membangun dan demi kemajuan sekolah, melibatkan guru dalam pengambilan keputusan yang berkaitan dengan pelaksanaan tugas demi kepentingan sekolah agar mampu membangun organisasi ke arah yang lebih baik.

\section{Kinerja Guru}

Berdasarkan data yang diperoleh dari responden dan dengan membandingkan skor rata-rata dengan skor maksimal dikali $100 \%$ dapat diketahui bahwa penilaian secara kuantitatif mengenai total quality management guru SMA/SMK di Kota Madiun berada pada kategori tinggi (78\% dari skor ideal). Hal ini berarti kinerja guru perlu untuk ditingkatkan agar menjadi lebih baik lagi.

Pengaruh Total quality management Dan Kedisiplinan Guru Terhadap Kinerja Guru 
Hasil pengujian hipotesis menunjukkan bahwa tidak ada pengaruh yang positif antara total quality management terhadap kinerja guru yaitu dengan diperolehmya rhitung $=-0,194<$ rtabel $=0,220$ pada taraf signifikan $95 \%$. Selanjutnya hasil pengujian hipotesis menunjukan bahwa ada pengaruh antara kedisiplinan guru terhadap kinerja guru yaitu dengan diperolehnya rhitung 0,512 $>0,220$ pada taraf signifikan $95 \%$.

Pengujian keberartian pengaruh antara total quality management terhadap kinerja guru dilakukan dengan menggunakan rumus uji t. Hasil pengujian membuktikan keberartian pengaruh tersebut dengan diperolehnya $t_{\text {hitung }}=-1,532<$ $\mathrm{t}_{\text {tabel }}=1,664$ pada taraf signifikan 95\%. Sedangkan keberartian pengaruh antara kedisiplinan guru terhadap kinerja guru dibuktikan dengan diperolehnya $t_{\text {hitung }}=$ $5,148>\mathrm{t}_{\text {tabel }}=1,664$ pada taraf signifikan $95 \%$.

Berdasarkan uraian di atas dapat disimpulkan bahwa total quality management tidak berpengaruh positif terhadap kinerja guru sedangkan kedisiplinan guru berpengaruh positif terhadap kinerja guru. Hasil penelitian ini memperlihatkan adanya pengaruh secara bersama-sama antara total quality management dan kedisiplinan guru terhadap kinerja guru, yaitu dengan perolehan hasil output SPSS Fhitung 15,275 dengan probabilitas $0,000<0,05$ yang berarti pula ada pengaruh secara simultan antara variabel total quality management (X1), kedisiplinan guru (X2) terhadap kinerja guru (Y).

\section{KESIMPULAN DAN SARAN}

Berdasarkan hasil penelitian di atas dapat disimpulkan bahwa total quality management berada pada kategori tinggi, kedisiplinan berada pada kategori tinggi dan kinerja guru berada pada kategori tinggi. Total quality management dan kedisiplinan guru berpengaruh terhadap kinerja guru SMA/SMK di kota Madiun. Artinya total quality management dan kedisiplinan merupakan salah satu faktor yang mempengaruhi kinerja guru. Seiring dengan kesimpulan diharapkan pengawas untuk melakukan pembinaan terhadap institusi (sekolah) yang di dalamnya terdapat banyak komponen yang harus dibina salah satunya adalah dengan menerapkan total quality management dan kedisiplinan guru agar meningkatkan kinerja guru SMA/SMK di Kota Madiun. Guru SMA/SMK di Kota Madiun, berdasarkan hasil penelitian total quality management berada pada kategori tinggi, kedisiplinan guru berada pada kategori tinggi dan kinerja guru berada pada kategori tinggi. Untuk itu diharapkan para guru memotivasi diri untuk berkembang dan menjadi lebih baik untuk meningkatkan kinerjanya serta bersikap secara profesional sebagai tenaga pendidik.

\section{DAFTAR PUSTAKA}

Bedjo Siswanto. 1989. Manajemen Tenaga Kerja. Bandung : Sinar Baru Dale Furtwengler. 2002. Penilaian Kinerja. Yogyakarta : ANDI. 
Dermawan Wibisono. 2011. Manajemen Kinerja (Konsep, Desain, Dan Teknik Meningkatkan Daya Saing Perusahaan. Jakarta : Pustaka Ilmu.

Fandy Tjiptono. 2002. Penilaian Kinerja. Yogyakarta : ANDI

H. Malayu S.P Hasibuan. 2008. Manajemen Sumber Daya Manusia. Jakarta :Bumi Aksara.

Jhon M. Invancevic dkk. 2007.Perilaku Dan Manajemen Organisasi. Jakarta : Erlangga.

Ngalim Purwanto. 2006. Ilmu Pendidikan Teoritis Dan Praktis. Bandung : Remaja Rosdakarya.

Suyadi Prawirosentono. 1999. Kebijakan Kinerja Karyawan. Yogyakarta : BPFE.

Wilson Bangun. 2012. Manajemen Sumber Daya Manusia. Jakarta : Erlangga. 